\title{
THE EFFECT OF PRESSURE ON SURFACE TENSION.
}

By C. J. Lynde.

THE following article is an account of an investigation into the effect of pressure on the surface tension of the surface between two liquids.

Method. - Briefly, the method was to place the heavier of the two liquids in a U-tube, one arm of which was $\mathrm{I} \mathrm{cm}$. in diameter and the other a capillary tube; this was immersed in the lighter liquid, a pressure of from $\mathrm{I}, 000$ to $6,000 \mathrm{lbs}$. per sq. in. was applied, and the change in the height of the meniscus in the capillary tube was observed by means of a micrometer microscope.

Apparatus. - The apparatus consisted essentially of: (I) A Utube with one arm a capillary tube (Figs. I and 2). (2) A compression chamber, with plunger, screw, and gauge (Figs. 3 and 4). (3) Two windows opposite each other in the compression chamber, through which the movement of the meniscus could be observed.

The U-tubes (Figs. I and 2) were $14 \mathrm{~cm}$. long, the larger upper tube being $9 \mathrm{~cm}$. long and $\mathrm{I} \mathrm{cm}$. in internal diameter; the smaller tube connecting with the capillary tube was $5 \mathrm{~cm}$. long and 0.5 $\mathrm{cm}$. in internal diameter. The bore of the capillary tube varied for the different observations. Their diameters are given with the following tables.

The compression chamber $C$ (Figs. 3 and 4 ) was of nickel steel $7.5 \mathrm{~cm}$. square and $37 \mathrm{~cm}$. long, the bore being $1.9 \mathrm{~cm}$. in diameter. It was divided into two parts at $a$ (Fig. 4) for the admission of the U-tube.

In the lower half, w. $w$. represent two cylindrical glass windows, I $4 \mathrm{~mm}$. deep and $\mathrm{I} 4 \mathrm{~mm}$. in diameter, cemented into hollow nickel steel plugs. The plugs were $33 \mathrm{~mm}$. long, and $50 \mathrm{~mm}$. in diameter at the head, and had a conical-shaped opening through the middle, which was $22 \mathrm{~mm}$. in diameter at the head and $5 \mathrm{~mm}$. in diameter at the windows. The upper half of the chamber screwed into 
the lower half, and a soft copper washer $A, 2 \mathrm{~mm}$. thick, served to make the juncture tight.

$B$ is a large plug $48 \mathrm{~mm}$. in diameter at the head and $50 \mathrm{~mm}$. deep, which screws into the chamber. It has a hole through the center, through which the plunger passes.

$P$ is a glass-hardened steel plunger $143 \mathrm{~mm}$. long and I $1.5 \mathrm{~mm}$. in diameter.

$D$ is a thin brass collar turned so as to fit the plunger accurately and so arranged (see Fig. 4) that the greater the pressure the tighter it holds.

$S$ is the screw which gives the downward motion to the plunger; it is $105 \mathrm{~mm}$. long and $\mathrm{I} 5 \mathrm{~mm}$. in diameter.

$G$ (Fig. 3) is a gauge reading as high as 20,000 lbs. per sq. inch.

$M$ is a micrometer microscope with focal length of $6 \mathrm{~cm}$. and I I divisions on the micrometer scale $=$ I mm.; IOO divisions on micrometer head $=\mathrm{I}$ division of micrometer scale.

\section{Method in Detall.}

Mercury and Water. - The U-tube (Fig. I) was cleaned carefully before each set of observations, by boiling it in strong sulphuric acid and dropping fragments of potassium bichromate into the liquid, so that the gas liberated passed up through the capillary tube; then it was boiled in distilled water, then rinsed with cold distilled water.

The mercury was triple-distilled and had been passed through dilute nitric acid solution.

The distilled water was freshly boiled and cooled. The mercury was poured into the U-tube, then placed under water and some of it forced out through the capillary tube, so that air, if present, was removed and a fresh water mercury surface secured.

The U-tube was then placed in the compression-chamber and adjusted so that the meniscus was in the field of view of the windows $w$, $w$.

The chamber was closed, filled with water, and the plunger and compression-screw adjusted.

The method of observation in all cases was to set the movable cross-hairs of the micrometer microscope on the meniscus, and read 
its position. An assistant put on the pressure; the new position was read, the pressure was let off, and the position to which the meniscus returned was read.

Each individual reading in the tables is a mean of a movement with pressure and a return-movement when the pressure was released.

In the early experiments with mercury and water it was impossible to observe any movement of the meniscus, and even when the

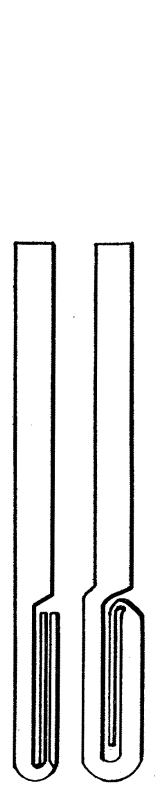

Fig. 1. Fig. 2.

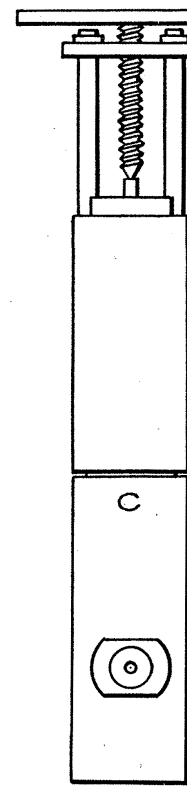

Fig. 3.

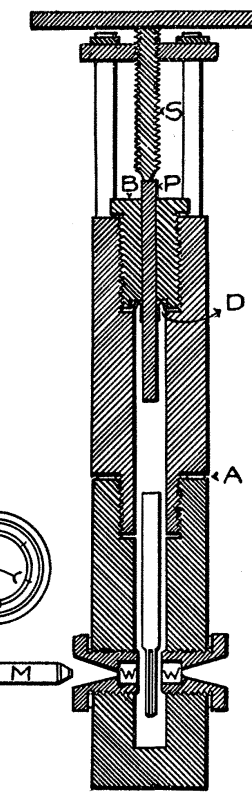

Fig. 4.

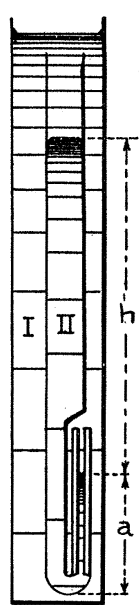

Fig. 5 .

U-tube was taken in the hand and tilted from side to side the movement was slow and irregular. This was thought to be due to the formation of an oxide of mercury at the surface of contact. The difficulty was overcome by adding nitric acid to make the water a 3 per cent. acid solution.

The difference in level of the mercury columns $h$ was measured by means of a cathetometer. 


\section{Method of Calculation.}

Let $T=$ surface tension of the contact surface.

$\theta=$ angle of contact.

$h=$ difference in height in $\mathrm{cm}$. of the columns of liquid II.

$r=$ radius of capillary bore.

$\sigma_{1}=$ density of liquid I.

$\sigma_{2}=$ density of liquid II.

$a=$ depth of liquid II. below meniscus.

Then

$$
T \cos \theta=\frac{h r}{2}\left(\sigma_{2}-\sigma_{1}\right)
$$

In this equation each term may vary with the pressure.

The change in $r$ can be neglected because, according to experiments of Amagat," the linear compression of glass is .0000007 5 per atmosphere. The highest pressure used in this investigation was in the neighborhood of 400 atmospheres and this would produce a change in $r$ of only .03 per cent., while the observed changes were all over I per cent. for this pressure.

From the experimental evidence at hand it appears that the contact angles of the surfaces employed in the present investigation are either $180^{\circ}$ or in the neighborhood of $180^{\circ}$, so that a variation of $\theta$ with pressure will cause but a small variation in $\cos \theta$, and in the present discussion this variation has been neglected. To determine rigorously what effect pressure produces on $\cos \theta$ will require a further investigation.

The variables then are $T, h, \sigma_{1}$ and $\sigma_{2}$. The changes in $\sigma_{1}$ and $\sigma_{2}$ may be calculated from the coefficients of compressibility and the pressure. The change in $h$ is that upon which the observations are made. From these the change in $T$ is calculated in the following way:

Differentiating Equation $\mathrm{I}$ as to $P$

$$
\frac{\delta T}{\delta P} \cos \theta=\frac{\delta h}{\delta P} \cdot \frac{r}{2}\left(\sigma_{2}-\sigma_{1}\right)+\frac{h r}{2}\left(\frac{\delta \sigma_{2}}{\delta P}-\frac{\delta \sigma_{1}}{\delta P}\right)
$$

Dividing by Equation I :

$$
\frac{1}{T} \frac{\delta T}{\delta P}=\frac{\mathrm{I}}{h} \cdot \frac{\delta h}{\delta P}+\frac{\overline{K_{2}}-\overline{K_{1}}}{\sigma_{2}-\sigma_{1}} .
$$

1 Wüllner, Vol. I., p. 238. 
In the present investigation $\delta P$ represented a change of pressure of I,Ooo pounds, $\therefore \bar{K}_{2}$ and $\bar{K}_{1}$ represented the change in $\sigma_{2}$ and $\sigma_{1}$ for a change of $\mathrm{I}, 000$ pounds in pressure.

\section{Summary of Measurements.}

I. $r$, the radius of the capillary tube, was measured by means of a micrometer microscope.

2. $h$, the difference of level of the liquid in the U-tube, was measured by means of a cathetometer. This difference of level could not be measured while the $\mathrm{U}$-tube was inside the compression-chamber, because the field of view through the windows was not great enough to include the upper and lower surface at the same time. In consequence $h$ was measured with the U.tube outside the compressionchamber.

3. $a$, the depth of the liquid in the U-tube below the meniscus (Fig. 5). This depth was also measured before the tube was placed in the compression-chamber.

4. $\delta h / \delta P$, the variation in height with change of pressure. The two surfaces could not be included in the field of view of the windows at one time. This was not necessary, however, for this measurement, because one arm of the U-tube being $10 \mathrm{~mm}$. in diameter and the other arm of capillary dimension, a considerable change in the level of the surface in the capillary-tube would produce a very small change in the level of the surface in the larger tube. Thus the change in the height of the meniscus gave at once the value of $\delta h / \delta P$.

This method of measuring $\delta h / \delta P$, leads to the following correction.

Correction. - The liquid in the U-tube which was below the level of the meniscus contracted in volume when pressure was applied. As the contraction was the same in both arms of the U-tube, it would have introduced no error into the readings of $\delta h / \delta P$ if these readings had been made by observing the upper and lower surfaces at the same time. As, however, the reading of $\delta h / \delta P$ was made by measurements in the change of level of the meniscus only, an error was introduced. The correction was made as follows :

Let $K=$ compressibility of the liquid per atmosphere at $25^{\circ} \mathrm{C}$. $a=$ depth in mm. of the liquid below the meniscus (Fig. 5). 


$$
\begin{aligned}
& p=\text { pressure in atmospheres. } \\
& C=\text { correction expressed in micrometer scale-divisions (I I } \\
& \quad \text { divisions }=\mathrm{I} \mathrm{mm} .) . \\
& C=\mathrm{I} \text { I apk. }
\end{aligned}
$$

Results for Mercury and Water.

$K$ for mercury per atm. at $25^{\circ} \mathrm{C} .=.000004$; for water $=.00004 \mathrm{I}$.

$\sigma_{2}$, density of mercury at $25^{\circ} \mathrm{C} .=\mathrm{I} 3.554 ; \sigma_{1}$, water at $25^{\circ} \mathrm{C}$. $=.997$.

$a=3 \mathrm{I} \mathrm{mm}$.

$C=.09$ divisions per $\mathrm{I}, 000$ pounds.

$$
\mathrm{IOO} \frac{\overline{K_{2}}-\overline{K_{1}}}{\sigma_{2}-\sigma_{1}}=.022 .
$$

The readings are the observed changes in the height of the meniscus expressed in scale divisions. When the readings are such that they would indicate a decrease in the surface-tension, a - sign is used; otherwise, no sign is used.

\begin{tabular}{|c|c|c|c|c|c|c|c|c|c|c|c|}
\hline 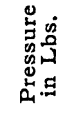 & I. & II. & III. & IV. & v. & VI. & Mean & $\begin{array}{c}\text { Mean } \\
\text { Corrected } \\
\text { for Com- } \\
\text { pression. }\end{array}$ & $\frac{100}{h} \cdot \frac{\delta h}{\delta P}$ & $100 \frac{\bar{K}_{2}-\bar{K}_{1}}{\sigma_{2}-\sigma_{\perp}}$ & $\frac{\text { roo }}{T} \cdot \frac{\delta T}{\delta P}$ \\
\hline 1,000 & 1.69 & 1.75 & 1.07 & .73 & .63 & .71 & 1.09 & 1.00 & .20 & -.02 & .18 \\
\hline 2,000 & 2.88 & 3.14 & 1.83 & 1.64 & 1.18 & 1.02 & 1.95 & 1.77 & .36 & -.04 & .32 \\
\hline 3,000 & 4.01 & 4.00 & 2.88 & 2.96 & 1.71 & 1.52 & 2.84 & 2.57 & .52 & -.06 & .46 \\
\hline 4,000 & 6.17 & 4.96 & 4.58 & 3.91 & 2.15 & 1.96 & 3.95 & 3.59 & .74 & -.09 & .65 \\
\hline 5,000 & 7.12 & 6.52 & 6.07 & 3.90 & 2.72 & 2.88 & 4.87 & 4.42 & .90 & -.11 & .79 \\
\hline 6,000 & 9.58 & 7.33 & 6.55 & 4.42 & 3.19 & 3.24 & 5.73 & 5.19 & 1.06 & -.13 & .93 \\
\hline
\end{tabular}

\section{Mercury and Water.}

$h=44 . \mathrm{I} \mathrm{mm}$.; diameters of the elliptical capillary bore $0.38 \mathrm{~mm}$., O. $19 \mathrm{~mm}$.

TAble I.

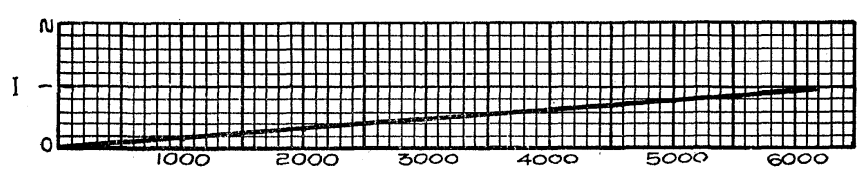


Mercury and Water.

Using a tube with a different capillary bore.

$h=\mathrm{I} 7.6 \mathrm{~mm}$; diameter of capillary bore $0.59 \mathrm{~mm}$.

TABLE II.

\begin{tabular}{l|r|r|r|r|r|r|r|r|r|c}
\hline \multicolumn{1}{c|}{$\begin{array}{c}\text { Pressure } \\
\text { in Lbs. }\end{array}$} & I. & II. & III. & IV. & V. & Mean. & $\begin{array}{c}\text { Mean } \\
\text { Corrected } \\
\text { for Com- } \\
\text { pression. }\end{array}$ & $\frac{\text { Ioo }}{h} \cdot \frac{\delta h}{\delta P}$ & Ioo $\frac{\bar{K}_{2}-\overline{K_{1}}}{\sigma_{2}-\sigma_{1}}$ & $\frac{\text { roo }}{T} \cdot \frac{\delta T}{\delta P}$ \\
\hline 1,000 (Calc.) & .49 & .30 & .26 & .52 & .52 & .42 & .33 & .17 & -.02 & .15 \\
2,000 & .72 & .70 & .59 & 1.04 & 1.13 & .84 & .66 & .34 & -.04 & .30 \\
3,000 & 1.52 & .83 & .83 & 1.69 & 1.69 & 1.31 & 1.04 & .54 & -.06 & .48 \\
4,000 & 1.96 & 1.02 & .99 & 2.09 & 2.09 & 1.63 & 1.27 & .66 & -.09 & .57 \\
5,000 & 1.99 & & 1.33 & 2.33 & 2.36 & 2.00 & 1.55 & .80 & -.11 & .69 \\
6,000 & 2.77 & 1.76 & 1.79 & 3.02 & 2.93 & 2.46 & 1.92 & .99 & -.13 & .86 \\
\hline
\end{tabular}

Conclusions. - (I) The surface-tension of the mercury-water surface increases with increase of pressure. (2) The percentageincrease is independent of the size of the capillary-tube. (3) The increase varies directly as the pressure.

\section{Mercury and Ether.}

Ether was substituted for water and the experiment repeated using the same tube as that for results in Table II. Here again it was necessary to add nitric acid to the ether, making it a three per cent. solution.

Corrections. $-K$ for mercury $=.000004$, for ether $=.000185$; $\sigma_{2}$ for mercury $=\mathrm{I} 3.554, \sigma_{1}$ for ether $=.7 \mathrm{I} 7 ; a=3 \mathrm{I} \mathrm{mm}$; $C=.09$ scale-divisions per $\mathrm{I}, 000 \mathrm{lbs}$;

$$
\mathrm{IOO} \frac{\bar{K}_{2}-\bar{K}_{1}}{\sigma_{2}-\sigma_{1}}=-.095
$$


TABLE III.

\begin{tabular}{l|c|c|c|c|c|c|c|c|c}
\multicolumn{8}{c}{$h=12.75 \mathrm{~mm} . ;$ diameter of capillary tube $=.59 \mathrm{~mm}}$. \\
\hline $\begin{array}{l}\text { Pressure } \\
\text { in Lbs. }\end{array}$ & I. & II. & III. & IV. & Mean. & $\begin{array}{c}\text { Mean } \\
\text { Corrected } \\
\text { for Com- } \\
\text { pression. }\end{array}$ & $\frac{100}{h} \cdot \frac{\delta h}{\delta P}$ & 100 $\frac{\bar{K}_{2}-\overline{K_{1}}}{\sigma_{2}-\sigma_{1}}$ & $\frac{100}{T} \cdot \frac{\delta T}{\delta P}$ \\
\hline 1,000 & .63 & .69 & .74 & .65 & .68 & .59 & .42 & -.09 & .33 \\
2,000 & 1.08 & 1.26 & 1.46 & 1.16 & 1.24 & 1.06 & .76 & -.19 & .57 \\
3,000 & 1.69 & 1.79 & 1.74 & 1.73 & 1.73 & 1.46 & 1.04 & -.28 & .76 \\
4,000 & 1.95 & 2.79 & 2.46 & 2.05 & 2.31 & 1.95 & 1.40 & -.38 & 1.02 \\
5,000 & & 3.32 & 2.91 & 2.32 & 2.85 & 2.40 & 1.71 & -.47 & 1.23 \\
\hline
\end{tabular}

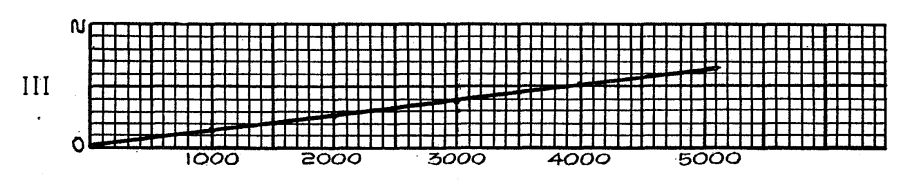

Conclusions. - (I) The surface-tension of the mercury-ether surface increases with increase of pressure. (2) The increase varies directly as the pressure.

\section{Watcr-Ether.}

In this case it was found undesirable to let the ether come in contact with the compression-chamber, because it rapidly dissolved the De Khotinski cement used in the joints of the pressure-gauge and about the windows. A tube of the form given in Fig. 2 was therefore used.

Ether was placed in the tube and water surrounded it. An inverted ether-column, was thus formed in the capillary tube and adjacent side-tube.

The method of observation was as above.

Corrections. $-K$ for water per atm. at $25^{\circ} \mathrm{C}=.000045$; for ether $=.000185 ; \sigma_{1}$ water per atm. at $25^{\circ} \mathrm{C} .=.997 ; \sigma_{2}$ for ether $=.7 \mathrm{I} 7 ; a=8 \mathrm{~mm} . ; C=\mathrm{I} . \mathrm{I} O$ divisions per I,O0O lbs.;

$$
100 \frac{\bar{K}_{2}-\bar{K}_{1}}{\sigma_{2}-\sigma_{1}}=-3.40 .
$$

Results for Ether and Water: $h=13 \mathrm{~mm}$.; diameter of capillary bore $0.59 \mathrm{~mm}$. 
No. 3.] EFFECT OF PRESSURE ON SURFACE TENSION. 189

TABLE IV.

\begin{tabular}{c|c|c|c|c|c|c|c|c|c}
\hline $\begin{array}{c}\text { Pressure } \\
\text { in Lbs. }\end{array}$ & I. & II. & III. & IV. & Mean. & $\begin{array}{c}\text { Mean } \\
\text { Corrected } \\
\text { for Com- } \\
\text { pression. }\end{array}$ & $\frac{\text { roo }}{h} \cdot \frac{\delta h}{\delta P}$ & Ioo $\frac{K_{2}-K_{1}}{\sigma_{2}-\sigma_{1}}$ & $\frac{\text { Ioo }}{T} \cdot \frac{\delta T}{\delta P}$ \\
\hline 1,000 & .15 & .32 & .16 & .20 & .21 & -.89 & -.67 & -3.40 & -4.07 \\
2,000 & .40 & .35 & .32 & .36 & .36 & -1.84 & -1.39 & -6.80 & -8.19 \\
3,000 & .42 & .40 & .41 & .38 & .40 & -2.90 & -2.19 & -10.20 & -12.39 \\
4,000 & .52 & .41 & .44 & .45 & .45 & -3.95 & -2.99 & -13.60 & -16.59 \\
5,000 & .66 & .56 & .50 & .59 & .58 & -4.92 & -3.73 & -17.00 & -20.73 \\
\hline
\end{tabular}

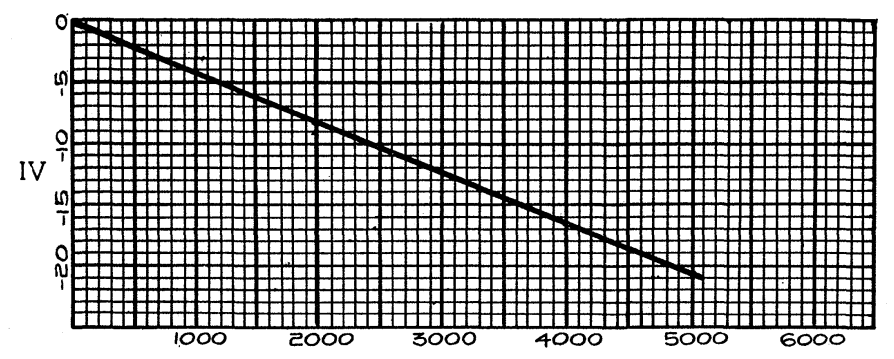

Graphical representation of the results given in Tables I.-V.

Conclusions. - (I) The surface-tension of the water-ether surface decreases with increase of pressure. (2) The decrease is proportional to the pressure.

\section{Chloroform and Water.}

Tube of form Fig. I used.

Corrections. $-K$ for chloroform per atm. at $25^{\circ} \mathrm{C} .=.000062$; for water $=.000045 ; \sigma_{2}$ for chloroform per atm. at $25^{\circ} \mathrm{C} .=\mathrm{I} .488$; $\sigma_{1}$ for water $=.997 ; a=38 \mathrm{~mm}$; $C=-\mathrm{I} .76$ divisions per I, 000 lbs.;

$$
\operatorname{IOO} \frac{\bar{K}_{2}-\bar{K}_{1}}{\sigma_{2}-\sigma_{1}}=.235
$$

Results for Chloroform and Water: $h=22.5 \mathrm{~mm}$.; diameter of capillary bore $=1.04 \mathrm{~mm}$. 
TABLE V.

\begin{tabular}{l|c|c|c|c|c|c|c|c|c}
\hline \hline $\begin{array}{c}\text { Pressure } \\
\text { in Lbs. }\end{array}$ & I. & II. & III. & IV. & Mean. & $\begin{array}{c}\text { Mean } \\
\text { Corrected } \\
\text { for Com- } \\
\text { pression. }\end{array}$ & $\frac{\text { Ioo }}{h} \cdot \frac{\delta h}{\delta P}$ & Ioo $\frac{\bar{K}_{2}-\overline{K_{1}}}{\sigma_{2}-\sigma_{1}}$ & $\frac{\text { Ioo }}{T} \cdot \frac{\delta T}{\delta P}$ \\
\hline 1,000 & .77 & 1.10 & 1.07 & 1.42 & 1.09 & -.67 & -.27 & .23 & -.04 \\
2,000 & 1.10 & 1.57 & 1.73 & 2.01 & 1.56 & -1.96 & -.71 & .47 & -.24 \\
3,000 & 1.70 & 2.02 & 3.09 & 2.64 & 2.36 & -2.92 & -1.18 & .70 & -.48 \\
4,000 & 2.93 & 2.67 & 4.14 & 3.68 & 3.35 & -3.69 & -1.49 & .94 & -.55 \\
5,000 & 2.54 & 4.07 & 4.86 & 4.92 & 4.09 & -4.71 & -1.90 & 1.17 & -.73 \\
\hline
\end{tabular}

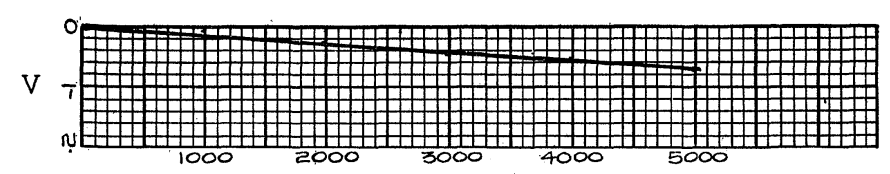

Conclusion. - (I) The surface-tension of the chloroform-water surface decreases with the pressure. (2) The decrease is proportional to the pressure.

\section{Carbon Bisulphide and Water.}

The carbon bisulphide was Karlbaum's best redistilled three times. The tube used was of form Fig. I.

Corrections. $-K$ for $C S_{2}$ per atm. at $25^{\circ} \mathrm{C} .=.000087$, for water $=.000045 ; \sigma_{2}$ for $C S_{2}$ per atm. at $25^{\circ} \mathrm{C} .=\mathrm{I} .265, \sigma_{1}$ for water $=.997 ; \alpha=20 \mathrm{~mm}$; $C=-\mathrm{I} .30$ divisions per $\mathrm{r}, 000 \mathrm{lbs}$;

$$
\text { IOO } \frac{\bar{K}_{2}-\bar{K}_{1}}{\sigma_{2}-\sigma_{1}}=1.36
$$

Results for Carbon Bisulphide and Water: $h=38.5$. Diameter of capillary bore $=1.38 \mathrm{~mm}$.

TABLE VI.

\begin{tabular}{c|c|c|c|c|c|c|c|c}
\hline $\begin{array}{c}\text { Pressure } \\
\text { in Lbs. }\end{array}$ & I. & II. & III. & Mean. & $\begin{array}{c}\text { Mean } \\
\text { Corrected } \\
\text { for Com- } \\
\text { pression. }\end{array}$ & $\frac{\text { Ioo }}{h} \cdot \frac{\delta h}{\delta P}$ & Ioo $\frac{\bar{K}_{2}-\overline{K_{1}}}{\sigma_{2}-\sigma_{1}}$ & $\frac{\text { roo }}{T} \cdot \frac{\delta T}{\delta P}$ \\
\hline 1,000 & -3.11 & -4.21 & -2.71 & -3.34 & -4.64 & -1.09 & 1.36 & .27 \\
2,000 & -5.78 & -4.81 & -4.41 & -5.00 & -7.60 & -1.79 & 2.72 & .93 \\
3,000 & -7.27 & -6.55 & -7.00 & -6.94 & -10.84 & -2.56 & 4.08 & 1.52 \\
4,000 & -8.71 & -7.50 & -7.22 & -7.81 & -13.01 & -3.07 & 5.44 & 2.37 \\
\hline
\end{tabular}


VI

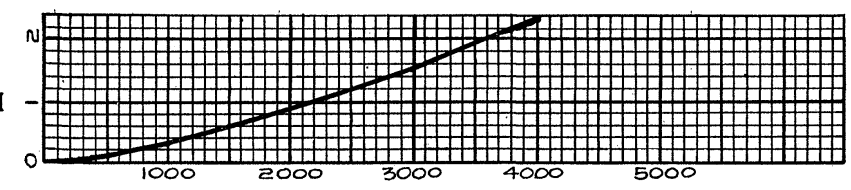

Conclusion. - The surface tension of the carbon-bisulphide-water surface increases with the pressure.

\section{Conclusions.}

I. The surface-tension of the contact-surface increases with increase of pressure in the cases of mercury-water, mercury-ether, and carbon-bisulphide-water.

2. The surface-tension of the contact-surface decreases with increase of pressure in the case of ether-water and chloroform-water.

3. The percentage-change is independent of the size of the capillary tube (Tables I. and II.).

4. The percentage-change is proportional to the pressure.

In conclusion I wish to thank Professor Michelson for suggesting the problem and the method of attack, and Professor Millikan for advice during the course of the work.

RYERSON LABORATORY,

The University of Chicago. 